\title{
G

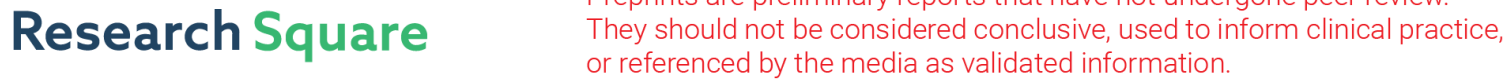 \\ Degeneration of lumbar paravertebral muscles in lumbar degenerative kyphosis with dynamic sagittal imbalance
}

$\mathrm{Nan} \mathrm{Ru}$

Cheeloo College of Medicine, Shandong University, Jinan, Shandong Province, China

\section{Guodong Wang}

Department of Spine Surgery, Shandong Provincial Hospital affiliated to Shandong First Medical University, No. 9677, Jingshi Road, Jinan, Shandong Province, China

\section{Yang Li}

Department of Spine Surgery, Shandong Provincial Hospital affiliated to Shandong First Medical University, No. 9677, Jingshi Road, Jinan, Shandong Province, China

\section{Xingang Cui}

Department of Spine Surgery, Shandong Provincial Hospital affiliated to Shandong First Medical University, No. 9677, Jingshi Road, Jinan, Shandong Province, China

Jianmin Sun ( $\nabla$ ru15621566510@163.com )

Department of Spine Surgery, Shandong Provincial Hospital affiliated to Shandong First Medical University, No. 9677, Jingshi Road, Jinan, Shandong Province, China

\section{Research Article}

Keywords: lumbar degenerative kyphosis, dynamic sagittal imbalance, paravertebral muscle; fat infiltration, muscle muscularity

Posted Date: May 14th, 2021

DOI: https://doi.org/10.21203/rs.3.rs-498662/v1

License: (c) (1) This work is licensed under a Creative Commons Attribution 4.0 International License. Read Full License 


\section{Abstract}

Background: The aim of this study was to probe the degeneration of lumbar paravertebral muscles in lumbar degenerative kyphosis (LDK) with dynamic sagittal imbalance (DSI).

Method: A total of 132 patients with LDK were enrolled in the study. According to the $\triangle$ SVA of the fullspine lateral radiographs before and after walking, enrolled patients were divided into two groups: DSI group (31 cases) and control group (42 case). Lumbar magnetic resonance imaging examination was taken for each subject. Fat infiltration area (FIA)and muscle muscularity of multifidus (MF) and erector spinae (ES) were quantitatively measured though Image $\mathrm{J}$ software. Independent-sample $t$ test were performed for comparison of quantitative variables between two groups. $P$ value $<0.05$ was considered statistically significant.

Result: DSI group had lower muscle muscularity both in ES and MF than control group. ES muscularity at L2 level was $0.42 \pm 0.08$ in DSI group and $0.82 \pm 0.17$ in control group. $(p=0.016)$. ES muscularity at L4 level was $0.36 \pm 0.11$ in DSI group and $0.76 \pm 0.22$ in control group. (pष0.001).MF muscularity at L2 level was $0.17 \pm 0.08$ in DSI group and $0.36 \pm 0.07$ in control group. (p $₫ 0.001$ ). MF muscularity at L4 level was $0.34 \pm 0.18$ in DSI group and $0.48 \pm 0.14$ in control group. (pष0.001).

DSI group had higher FIA both in ES and MF than control group.ES FIA at L2 level was $0.50 \pm 0.17$ in DSI group and $0.31 \pm 0.10$ in control group. $(p=0.023)$. ES FIA at L4 level was $0.55 \pm 0.27$ in DSI group and $0.34 \pm 0.07$ in control group. (p\0.001).MF FIA at L2 level was $0.63 \pm 0.22$ in DSI group and $0.36 \pm 0.12$ in control group. (pष0.001). MF FIA at L4 level was $0.76 \pm 0.31$ in DSI group and $0.40 \pm 0.19$ in control group. $(\mathrm{p} \otimes 0.001)$.

Conclusions: LDK patients with DSI suffered lower muscle muscularity and higher FIA both in ES and MF compared to control group. Our study revealed that the weakness of the paravertebral muscles plays an important role in DSI process, targeted paravertebral muscle strengthening training may be a potentially effective treatment for this disease.

\section{Introduction}

Lumbar degenerative kyphosis (LDK) is a common problem in elderly population, especially in the Asian population[1, 2]. It is considered as sagittal imbalance due to marked loss of lumbar lordosis or lumbar kyphosis[3]. This disease brings immense burdens to the social economy and families.

Takemitsu et al. classified LDK into 4 types and revealed the pathology as disc narrowing, collapsed vertebral bodies due to osteoporosis, and lumbar paravertebral muscle atrophy[3]. Yagi et al. redefined LDK as drop body syndrome (DBS) due to tremendous increased sagittal vertical axis (SVA)[4, 5]. These diseases share similar characteristics of decreased lumbar lordosis or lumbar kyphosis, decreased crosssectional area (CSA) and increased fatty infiltration area (FIA) of lumbar paravertebral muscles[2, 4]. 
Bae $\mathrm{J}$ firstly described dynamic sagittal imbalance (DSI) in flat back syndrome[6]. Zhou et al. proposed a novel classification for DSI and its quantitative diagnostic criteria: pre-walk SVA $<40 \mathrm{~mm}$ and post-walk SVA-pre-walk SVA $\geq 20 \mathrm{~mm}(\triangle S V A)$ after 10-min walk[7]. DSI is also the character of LDK[2, 8]. However, in clinical practice we found that some LDK patients could maintain sagittal balance persistently during walking ('compensated' group), whereas some LDK patients complained about obvious stooping trunk after walking/activity ('decompensated' group).

These previous studies used 3D-gait analysis and lateral full-spine radiographs to examine detailed changes in spinal sagittal parameters in DSI[6, 7, 9]. However, to the best of our knowledge, the differences between 'compensated' group and 'decompensated' group in paravertebral muscle degeneration have not been studied before.

\section{Materials And Methods}

A total of 132 patients with LDK were enrolled in the study between March 2018 and May 2020. (The detailed flowchart is shown in Fig. 1.) All enrolled patients with LDK were asked to take two sets of lateral full-spine standing radiographs at initiation and after a 10-min walk at their usual speed. Any kind of rest was prohibited in this 10-min walk test. Two well-trained spine surgeons would supervise each participant for the entirety of the 10-mins walk test[7]. Finally, 31 patients were included in the DSI group (Decompensated group).

Inclusion criteria[2, 7]: patients with LDK, pre-walk SVA $<40 \mathrm{~mm}$ and post-walk SVA-pre-walk SVA $\geq 20$ $\mathrm{mm}(\triangle \mathrm{SVA})$ after 10-min walk.

Exclusion criteria: spondylolysis/spondylolisthesis, congenital or neuromuscular scoliosis, post-traumatic kyphosis, hip joint or pelvic diseases, lower limb diseases such as osteoarthritis or ankle diseases, acute vertebral compression fracture, lumbar disc herniation/lumbar spinal stenosis with radicular symptoms, Scheuermann kyphosis and Cobb angle $>30^{\circ}$.

Among the remaining participants, in order to reduce bias because of obesity and age, the participants were well matched with the DSI patients based on body mass index (BMI) and age. Finally, a total of 42 participants were included in the control group (Compensated group). Numeric Rating Scales (NRS, 010) for low back pain and Oswestry Disability Index (ODI) scores were routinely collected. Written informed consent was obtained from all subjects. This study was approved by the Ethics Committee of local institution.

\section{Paravertebral Muscle Evaluation}

All subjects underwent lumbar MRI (magnetic resonance imaging) examination. MRI was performed by 1.5T Magnetom Vision scanners (Magnetom Symphony; Siemens, Berlin, Germany). The original T2weighted axial images were imported into Image $J$ (Version 1.52a. National Institutes of Health. USA) for analysis. The contours of the multifidus (MF) and erector spinae (ES) are outlined manually using Image 
J. (Fig. 2.A) ES and MF were evaluated at the midlevel of L2 and L4 level bilaterally. The muscle fat infiltration area was estimated using the subcutaneous fat threshold as the standard[10, 11]. (Fig. 2.B) In order to compensate for the bias of individual body size, we introduced muscle muscularity[12], which was defined as the ratio of CSA of muscle to CSA of L4 vertebrae body. The FIA in each muscle was evaluated: the ratio of fat infiltration area to total CSA. CSA of muscle was calculated as the mean value of bilateral CSA. All data was assessed twice by two independent spinal surgeons, and the average value was calculated as the final result.

\section{Statistical analysis}

Statistical analysis was performed using SPSS (IBM Inc., Chicago, IL, US). The normality of the data was tested by the Shapiro-Wilk test firstly. Independent-sample $t$ test were performed for comparison of quantitative variables between two groups. All data were presented as mean values \pm SEM (standard error of the mean). $P$ value $<0.05$ was considered statistically significant.

\section{Results}

DSI group was comprised of 3 men and 28 women (age, $63.7 \pm 4.8$ years old; height, $159.8 \pm 6.3 \mathrm{~cm}$; and $\mathrm{BMI}, 25.0 \pm 3.3$ ). The control group was comprised of 2 men and 40 women (age, $63.5 \pm 4.1$ years old; height, $158.3 \pm 6.4 \mathrm{~cm}$; and $\mathrm{BMI}, 23.9 \pm 3.4$ ). There were no significant difference in age, height, or BMI between two groups.

There was either no significant difference in NRS for low back pain between two groups. Statistically significant difference was observed for ODI scores between both two groups, DSI group had higher ODI scores $(17.7 \pm 4.6)$ than the control group $(14.7 \pm 6.9)(p=0.02)$. Detailed results are described in Table 1 .

Table 1

Comparison of demographic data in DSI group and control group

\begin{tabular}{|llll|}
\hline Parameters & DSI $(\mathbf{n}=\mathbf{3 1})$ & Controls $(\mathbf{n}=\mathbf{4 2})$ & P value \\
\hline Age $(\mathbf{y})$ & $63.7 \pm 4.8$ & $63.5 \pm 4.1$ & 0.545 \\
\hline BMI $\left(\mathrm{kg} / \mathrm{m}^{2}\right)$ & $25.0 \pm 3.3$ & $23.9 \pm 3.4$ & 0.176 \\
\hline Heights $(\mathrm{cm})$ & $159.8 \pm 6.3$ & $158.3 \pm 6.4$ & 0.638 \\
NRS for back pain & $2.6 \pm 0.7$ & $2.7 \pm 0.6$ & 0.342 \\
ODI & $17.7 \pm 4.6$ & $14.7 \pm 6.9$ & $0.002^{*}$ \\
\hline $\begin{array}{l}\text { BM body mass index, ODI Oswestry Disability Index, NRS Numeric Rating Scales, * Statistical } \\
\text { significance. }\end{array}$ & \\
\hline
\end{tabular}

DSI group had lower muscle muscularity both in ES and MF than control group. ES muscularity at L2 level was $0.42 \pm 0.08$ in DSI group and $0.82 \pm 0.17$ in control group. $(p=0.016)$. ES muscularity at L4 level was $0.36 \pm 0.11$ in DSI group and $0.76 \pm 0.22$ in control group. (pष0.001).MF muscularity at L2 level was 
$0.17 \pm 0.08$ in DSI group and $0.36 \pm 0.07$ in control group. (pख0.001). MF muscularity at L4 level was 0.34

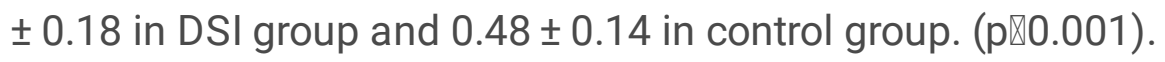

DSI group had higher FIA both in ES and MF than control group. ES FIA at L2 level was $0.50 \pm 0.17$ in DSI group and $0.31 \pm 0.10$ in control group. $(p=0.023)$. ES FIA at L4 level was $0.55 \pm 0.27$ in DSI group and $0.34 \pm 0.07$ in control group. (pष0.001).MF FIA at L2 level was $0.63 \pm 0.22$ in DSI group and $0.36 \pm 0.12$ in control group. (p\0.001). MF FIA at L4 level was $0.76 \pm 0.31$ in DSI group and $0.40 \pm 0.19$ in control group. (pख0.001). Detailed results are described in Table 2.

Table 2

Comparison of $\mathrm{FI}$ and muscle muscularity in DSI group and control group

\begin{tabular}{|c|c|c|c|c|c|}
\hline & Levels & Muscles & DSI $(n=31)$ & Controls $(n=42)$ & $P$ value \\
\hline & L2 & MF & $0.63 \pm 0.22$ & $0.36 \pm 0.12$ & $\otimes 0.001 *$ \\
\hline \multirow[t]{4}{*}{ FIA } & & ES & $0.50 \pm 0.17$ & $0.31 \pm 0.10$ & $0.023^{*}$ \\
\hline & L4 & MF & $0.76 \pm 0.31$ & $0.40 \pm 0.19$ & $\otimes 0.001 *$ \\
\hline & & ES & $0.55 \pm 0.27$ & $0.34 \pm 0.07$ & $\otimes 0.001 *$ \\
\hline & L2 & MF & $0.17 \pm 0.08$ & $0.36 \pm 0.07$ & $\otimes 0.001^{*}$ \\
\hline \multirow{3}{*}{$\begin{array}{l}\text { Muscle } \\
\text { muscularity }\end{array}$} & & ES & $0.42 \pm 0.08$ & $0.82 \pm 0.17$ & $0.016^{*}$ \\
\hline & L4 & MF & $0.34 \pm 0.18$ & $0.48 \pm 0.14$ & $\nabla 0.001^{*}$ \\
\hline & & ES & $0.36 \pm 0.11$ & $0.76 \pm 0.22$ & $\otimes 0.001 *$ \\
\hline
\end{tabular}

\section{Discussion}

LDK was characterized by degenerative loss of lumbar lordosis or flatback syndrome without a history of prior spinal surgery[3]. It is more frequently reported in Asian population than in western countries[2, 13]. Some researchers argued that LDK is caused by unique life styles such as the prolonged crouched posture during agricultural work and performing activities of daily living on the floor[13]. Typically, LDK is categorized as ' $\mathrm{N}$ type' according to SRS-Schwab ASD classification[14].

DSI was first systematically reported by Bae[6], he introduced the method of taking two sets of lateral fullspine standing radiographs at initiation and after a 10-min walk to assess DSI. In this study, different compensatory changes of sagittal parameters were studied in 'compensated 'group and 'decompensated' group, respectively. Recently, Zhou et al. investigated more detailed changes of sagittal parameters in 'decompensated' group[7]. Moreover, Lee found that the good compensation of the pelvis determines the outcome of surgery in DSI[9]. In a word, DSI is a dynamic process which is associated with different 
changes of sagittal parameters. Although the above studies speculated that there was weakness of paravertebral muscles, no further investigation was did.

The compensatory mechanisms for sagittal imbalance are very complex, which include reduction in TK, hyperextension in lumbar, retroversion of pelvis, and lower extremities-related compensatory mechanisms $[15,16]$. All those mentioned above compensatory mechanisms depend on contraction and interaction between gluteus, quadriceps femoris, iliopsoas and paravertebral muscles, etc[17].

Paravertebral muscles have long been viewed as important factors in maintaining sagittal balance. MF and ES have gained more attention for their functions. Anatomically, MF and ES connect the lumbar spine to the pelvis, MF is usually divided into two layers, the superficial multifidus is responsible for lumbar extension and the deep multifidus for intersegmental stability $[18,19]$. Whereas the ES play a key role in extending the spine and maintaining spinal balance against body weight[20]. Moreover,

previous studies have demonstrated that changes in spino-pelvic parameters is strongly associated with a decrease in the mass of the MF, ES as well as psoas[19, 21, 22]. Once the muscles degenerate, it will inevitably affect the compensation mechanism, which will lead to the sagittal imbalance.

There is no doubt that the spine sequence is the primary factor affecting the sagittal balance of the spine. In LDK, in addition to the sagittal imbalance caused by marked loss of lumbar lordosis or lumbar kyphosis itself, the fatigue of back extensor muscles would further accelerate sagittal imbalance[11, 23]. The results of biomechanical experiments and surface electromyography have confirmed the significantly increased activity in the paravertebral muscles of $\operatorname{LDK}[2,24,25]$. For LDK patients, better paravertebral muscle function is needed to maintain ideal spinal balance.

In present study, we found that patients in the control group also have a certain degree of paravertebral muscle degeneration, but DSI group suffered lower muscle muscularity and higher FIA both in ES and MF than control group. High FI rate and low muscle muscularity always represent decreased muscle power and poor fatigue resistance[25,26]. In control group, strong muscle power and good fatigue resistance of paravertebral muscles keep the spine always in good balance permanently. Whereas in DSI group, decreased quantity and quality of paravertebral muscles lead to sagittal imbalance quickly even in 10min walk. The representative cases are shown in Fig. 3

and Fig. 4. Therefore, our study revealed that the weakness of the paravertebral muscles plays an important role in the DSI process, which remind spinal surgeons that targeted muscle strengthening training may be an effective treatment for LDK with DSI. Previous studies have proved that targeted muscle strengthening training can effectively prevent spinal sagittal imbalance and improve ODI[19, 25].

In summary, DSI is the result of the continuous interaction of the spinal sequence and the paravertebral muscle. A bad spinal sequence such as LDK only represent a strong propensity to fatigue for paravertebral muscles, which could accelerate sagittal imbalance. Another decisive factor is that the 
strength and fatigue resistance of paravertebral muscles. Good muscle function could combat this propensity to fatigue, which would keep sagittal balance persistently.

The present study has some limitations that need further discussion and investigation. First, an inherent limitation of this study is the sample size. Small sample size limited the ability to conduct more detailed groups for analysis. Second, the compensatory mechanisms of lower extremities have not been taken into account in this study. Full-body radiographs and 3D gait analysis are needed to evaluate the effect of lower limbs in further plan. Finally, the potential degeneration of other muscles involved in pelvic compensation such as gluteus and iliopsoas were not explored. MR of the pelvis and lower limbs are needed for further exploration in next step.

\section{Conclusions}

LDK patients with DSI suffered lower muscle muscularity and higher FIA both in ES and MF compared to LDK patients without DSI. Our study revealed that the weakness of the paravertebral muscles plays an important role in the DSI process, targeted paravertebral muscle strengthening training may be a potentially effective treatment for this disease.

\section{Declarations}

The study was approved by Ethics Committee of of local institution. All methods were carried out in accordance with relevant guidelines and regulations.

\section{Ethics approval and consent to participate}

The participants provided written informed consent to participate in this research. The subjects' rights and interests are protected well in the whole process. The research has been approved by Medical Ethics Committee of Shandong Provincial Hospital affiliated to Shandong First Medical University

\section{Consent for publication}

The images appearing in Figs. 2.3. and 4 are published with consent.

\section{Availability of data and materials}

All datasets on which the conclusions of the manuscript rely were presented in the main paper.

\section{Competing interests}

The authors declare that they have no competing interests.

\section{Funding}

This article did not receive any funding. 
Authors' contributions

Jianmin Sun and Guodong Wang thought out the study, participated in its design and

coordination. Nan Ru carried out this study, did the statistics and drafted the manuscript. Xingang Cui polished the manuscript. Yang Li collected the image data of patients. All authors read and approved the final manuscript.

\section{Acknowledgements}

The authors thank the Department of Imaging in Shandong Provincial Hospital affiliated to Shandong First Medical University for providing the image data of patients.

\section{Abbreviations}

LDK, lumbar degenerative kyphosis; DBS, drop body syndrome; SVA, increased sagittal vertical axis; CSA, cross-sectional area; FIA, increased fatty infiltration area;

DSI, dynamic sagittal imbalance; $\triangle$ SVA, post-walk SVA-pre-walk SVA; BMI, body mass index; NRS, Numeric Rating Scales; ODI, Oswestry Disability Index; MRI, magnetic resonance imaging; MF, multifidus, ES, erector spinae

\section{References}

1. Lee JH, Kim KT, Suk KS, Lee SH, Jeong BO, Kim JS, Eoh JH, Kim YJ: Analysis of spinopelvic parameters in lumbar degenerative kyphosis: correlation with spinal stenosis and spondylolisthesis. Spine 2010, 35(24):E1386-1391.

2. Jang JS, Lee SH, Min JH, Han KM: Lumbar degenerative kyphosis: radiologic analysis and classifications. Spine 2007, 32(24):2694-2699.

3. Takemitsu Y, Harada Y, Iwahara T, Miyamoto M, Miyatake Y: Lumbar degenerative kyphosis. Clinical, radiological and epidemiological studies. Spine 1988, 13(11):1317-1326.

4. Yagi M, Kaneko S, Yato Y, Asazuma T: Drop Body Syndrome: A Distinct Form of Adult Spinal Deformity. Spine 2017, 42(16):E969-e977.

5. Yagi M, Fujita N, Okada E, Tsuji O, Nagoshi N, Yato Y, Asazuma T, Nakamura M, Matsumoto M, Watanabe K: Surgical Outcomes for Drop Body Syndrome in Adult Spinal Deformity. Spine 2019, 44(8):571-578.

6. Bae J, Theologis AA, Jang JS, Lee SH, Deviren V: Impact of Fatigue on Maintenance of Upright Posture: Dynamic Assessment of Sagittal Spinal Deformity Parameters After Walking 10 Minutes. Spine 2017, 42(10):733-739.

7. Yin J, Ma X, Lin T, Gao R, Zhou X: Characteristics and treatment of dynamic sagittal imbalance in adult spinal deformity. European spine journal : official publication of the European Spine Society, the 
European Spinal Deformity Society, and the European Section of the Cervical Spine Research Society 2020, 29(9):2340-2353.

8. Son SM, Shin JK, Goh TS, Suh KT, Lee JS: Predictive Findings of the Presence of Stooping in Patients With Lumbar Degenerative Kyphosis by Upright Whole Spine Lateral Radiography. Spine 2018, 43(8):571-577.

9. Lee CS, Lee CK, Kim YT, Hong YM, Yoo JH: Dynamic sagittal imbalance of the spine in degenerative flat back: significance of pelvic tilt in surgical treatment. Spine 2001, 26(18):2029-2035.

10. Ranson CA, Burnett AF, Kerslake R, Batt ME, O'Sullivan PB: An investigation into the use of MR imaging to determine the functional cross sectional area of lumbar paraspinal muscles. European spine journal : official publication of the European Spine Society, the European Spinal Deformity Society, and the European Section of the Cervical Spine Research Society 2006, 15(6):764-773.

11. Hyun SJ, Bae CW, Lee SH, Rhim SC: Fatty Degeneration of the Paraspinal Muscle in Patients With Degenerative Lumbar Kyphosis: A New Evaluation Method of Quantitative Digital Analysis Using MRI and CT Scan. Clinical spine surgery 2016, 29(10):441-447.

12. Hyun SJ, Kim YJ, Rhim SC: Patients with proximal junctional kyphosis after stopping at thoracolumbar junction have lower muscularity, fatty degeneration at the thoracolumbar area. The spine journal : official journal of the North American Spine Society 2016, 16(9):1095-1101.

13. Lee CH, Chung CK, Jang JS, Kim SM, Chin DK, Lee JK: 'Lumbar Degenerative Kyphosis' Is Not Byword for Degenerative Sagittal Imbalance: Time to Replace a Misconception. Journal of Korean Neurosurgical Society 2017, 60(2):125-129.

14. Schwab F, Ungar B, Blondel B, Buchowski J, Coe J, Deinlein D, DeWald C, Mehdian H, Shaffrey C, Tribus $C$ et al: Scoliosis Research Society-Schwab adult spinal deformity classification: a validation study. Spine 2012, 37(12):1077-1082.

15. Barrey C, Roussouly P, Le Huec JC, D'Acunzi G, Perrin G: Compensatory mechanisms contributing to keep the sagittal balance of the spine. Eur Spine J 2013, 22 Suppl 6:S834-841.

16. Hey HWD, Tan KA, Thadani VN, Liu GK, Wong HK: Characterization of Sagittal Spine Alignment With Reference to the Gravity Line and Vertebral Slopes: An Analysis of Different Roussouly Curves. Spine 2020, 45(9):E481-e488.

17. Diebo BG, Varghese JJ, Lafage R, Schwab FJ, Lafage V: Sagittal alignment of the spine: What do you need to know? Clinical neurology and neurosurgery 2015, 139:295-301.

18. Goubert D, De Pauw R, Meeus M, Willems T, Cagnie B, Schouppe S, Van Oosterwijck J, Dhondt E, Danneels $L$ : Lumbar muscle structure and function in chronic versus recurrent low back pain: a cross-sectional study. The spine journal : official journal of the North American Spine Society 2017, 17(9):1285-1296.

19. Katsu M, Ohba T, Ebata S, Oba H, Koyama K, Haro H: Potential Role of Paraspinal Musculature in the Maintenance of Spinopelvic Alignment in Patients With Adult Spinal Deformities. Clinical spine surgery 2020, 33(2):E76-e80. 
20. Tveit $P$, Daggfeldt $K$, Hetland $S$, Thorstensson A: Erector spinae lever arm length variations with changes in spinal curvature. Spine 1994, 19(2):199-204.

21. Xia W, Fu H, Zhu Z, Liu C, Wang K, Xu S, Liu H: Association between back muscle degeneration and spinal-pelvic parameters in patients with degenerative spinal kyphosis. BMC musculoskeletal disorders 2019, 20(1):454.

22. Masaki M, Ikezoe T, Fukumoto Y, Minami S, Tsukagoshi R, Sakuma K, Ibuki S, Yamada Y, Kimura M, Ichihashi N: Association of sagittal spinal alignment with thickness and echo intensity of lumbar back muscles in middle-aged and elderly women. Archives of gerontology and geriatrics 2015, 61(2):197-201.

23. Banno T, Yamato Y, Hasegawa T, Kobayashi S, Togawa D, Oe S, Mihara Y, Kurosu K, Yamamoto N, Matsuyama Y: Assessment of the Cross-Sectional Areas of the Psoas Major and Multifidus Muscles in Patients With Adult Spinal Deformity: A Case-Control Study. Clinical spine surgery 2017, 30(7):E968-e973.

24. Enomoto M, Ukegawa D, Sakaki K, Tomizawa S, Arai Y, Kawabata S, Kato T, Yoshii T, Shinomiya K, Okawa A: Increase in paravertebral muscle activity in lumbar kyphosis patients by surface electromyography compared with lumbar spinal canal stenosis patients and healthy volunteers. Journal of spinal disorders \& techniques 2012, 25(6):E167-173.

25. Jun HS, Kim JH, Ahn JH, Chang IB, Song JH, Kim TH, Park MS, Chan Kim Y, Kim SW, Oh JK et al: The Effect of Lumbar Spinal Muscle on Spinal Sagittal Alignment: Evaluating Muscle Quantity and Quality. Neurosurgery 2016, 79(6):847-855.

26. Zotti MGT, Boas FV, Clifton T, Piche M, Yoon WW, Freeman BJC: Does pre-operative magnetic resonance imaging of the lumbar multifidus muscle predict clinical outcomes following lumbar spinal decompression for symptomatic spinal stenosis? European spine journal : official publication of the European Spine Society, the European Spinal Deformity Society, and the European Section of the Cervical Spine Research Society 2017, 26(10):2589-2597.

\section{Figures}




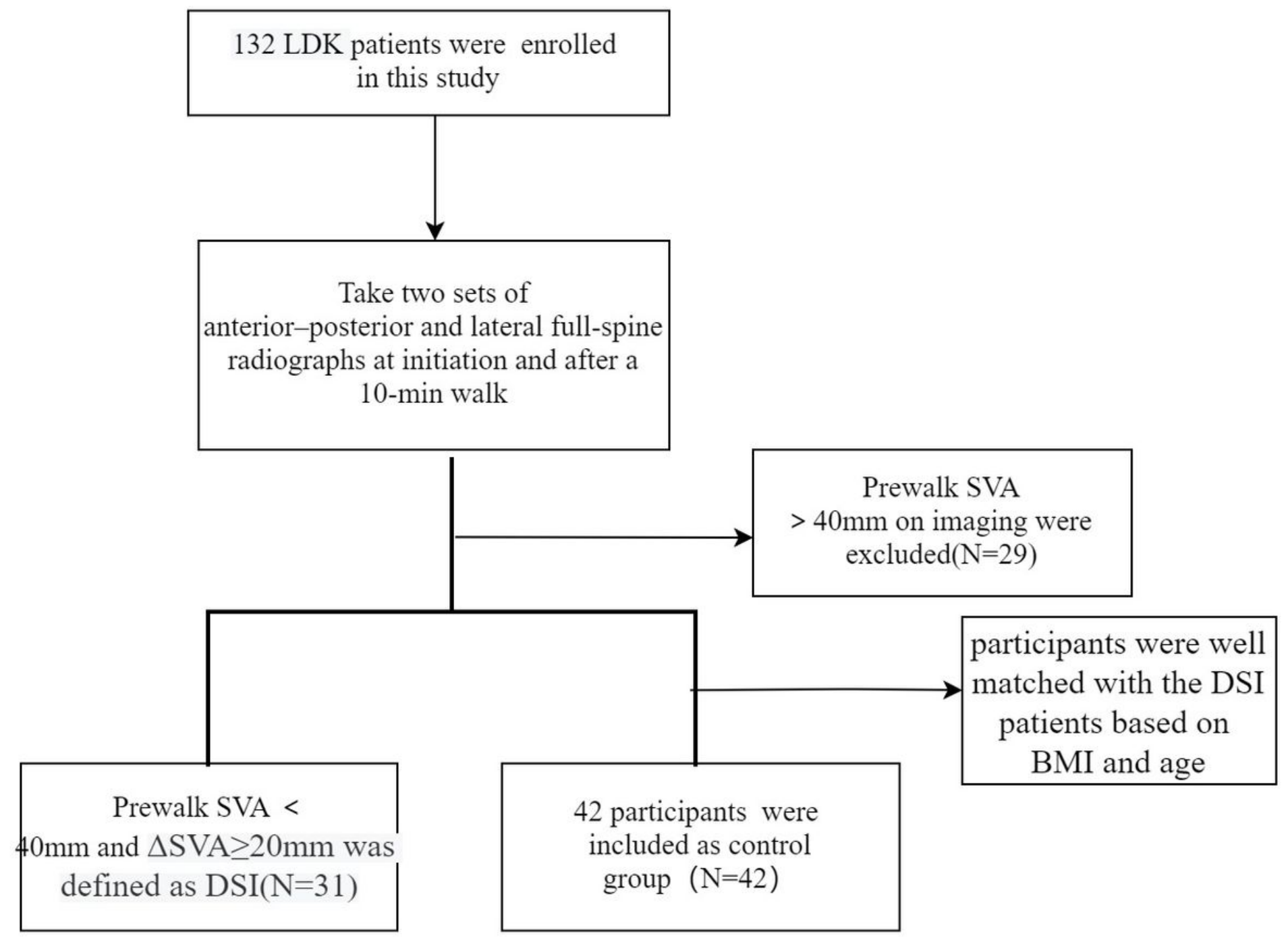

Figure 1

Flow chart of study processing. 


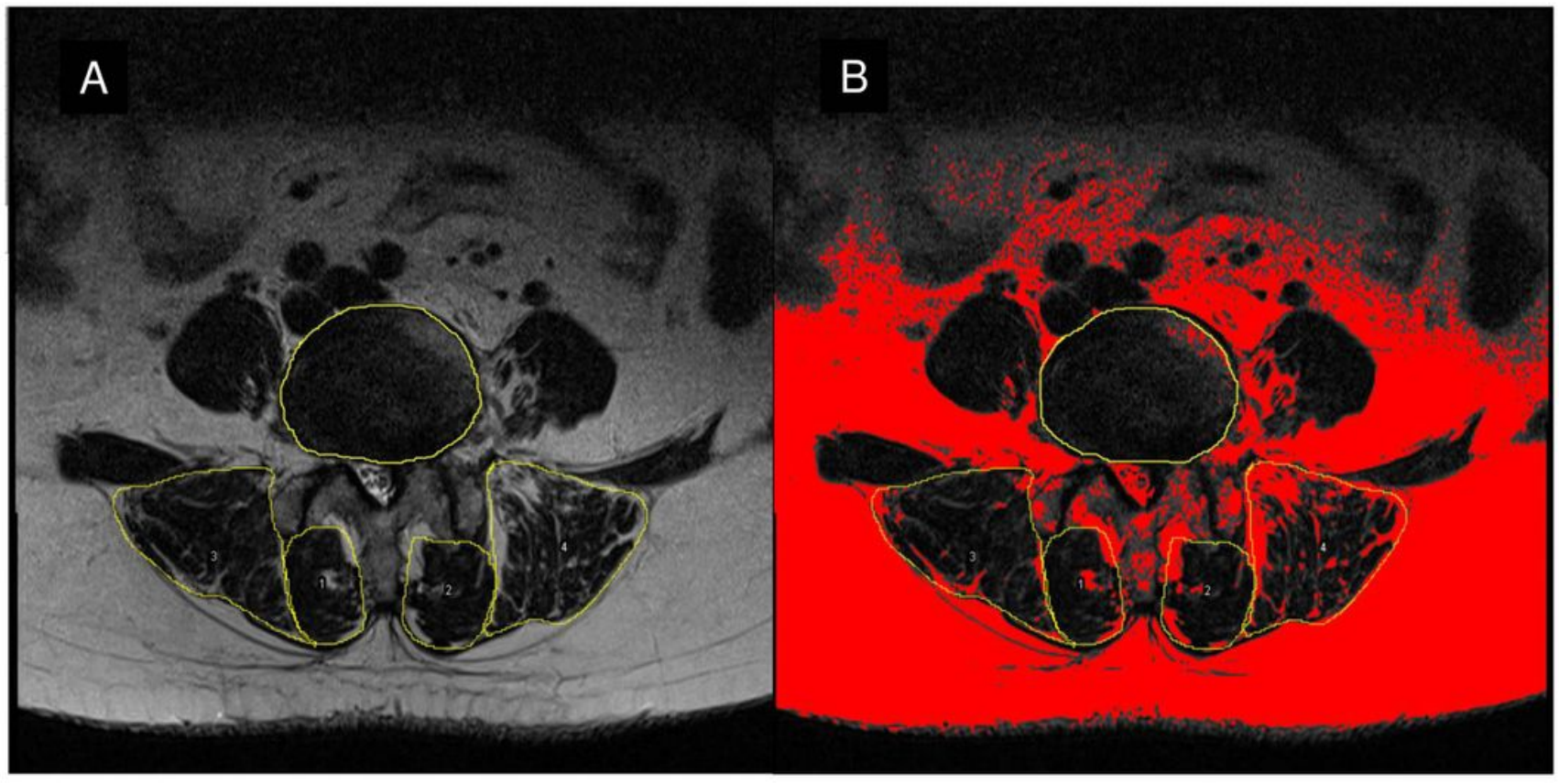

Figure 2

A: The contours of the multifidus, erector spinae were outlined manually using Image J. B: Muscle fat infiltration $(\mathrm{FI})$ area was estimated using the subcutaneous fat threshold as the standard. 


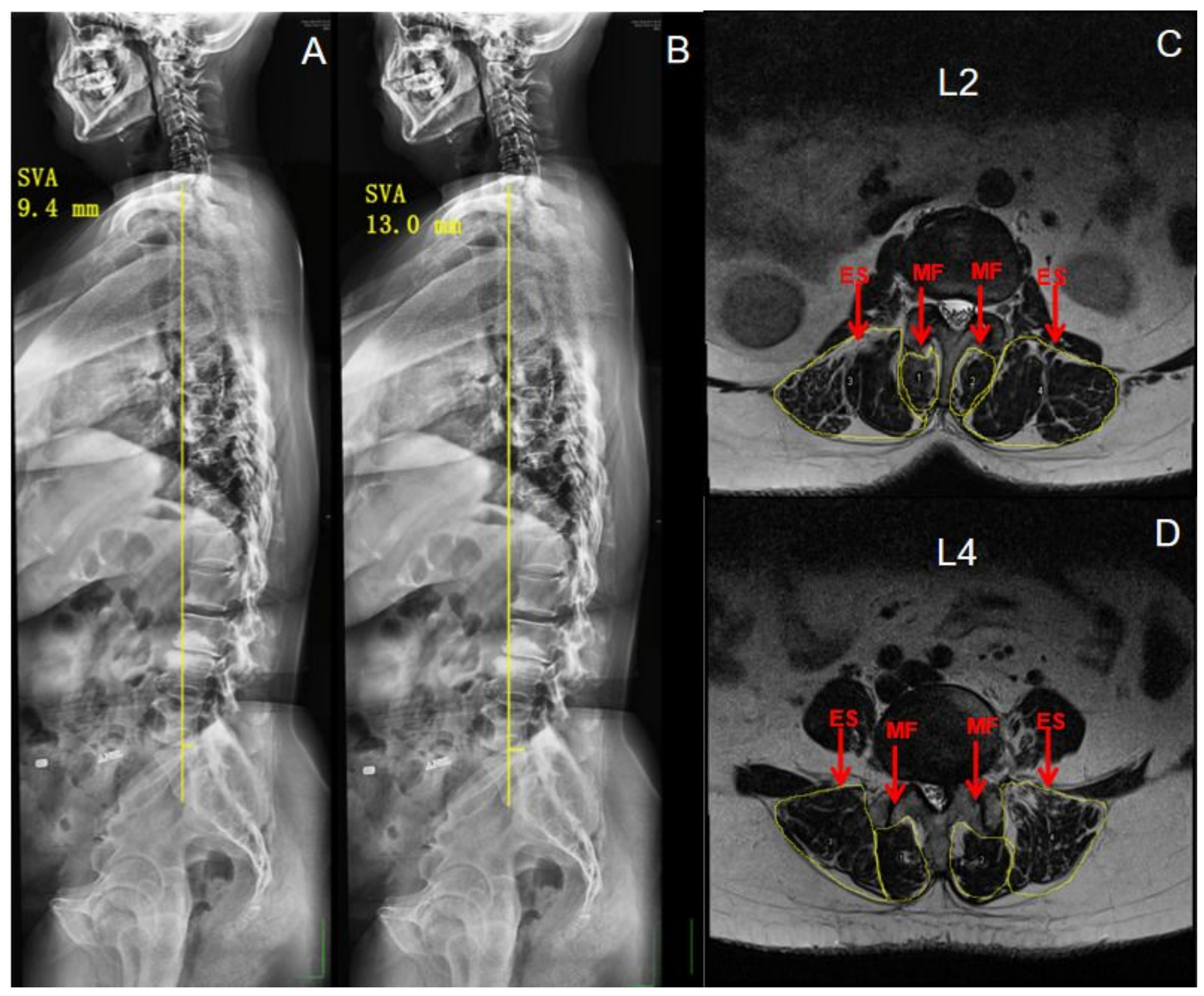

Figure 3

Case 1. Female, 64 years old. A:Lateral full-spine standing radiographs at initiation shows normal $S V A(S V A=9.4 \mathrm{~mm}) \cdot B: S V A$ after 10 -minute walk test remains normal ( $S V A=13.1 \mathrm{~mm}, \Delta S V A=3.7 \mathrm{~mm}) . C \otimes D:$ No obvious fat infiltration and paravertebral muscle degeneration was found at $L 2$ and $L 4$ levels. 


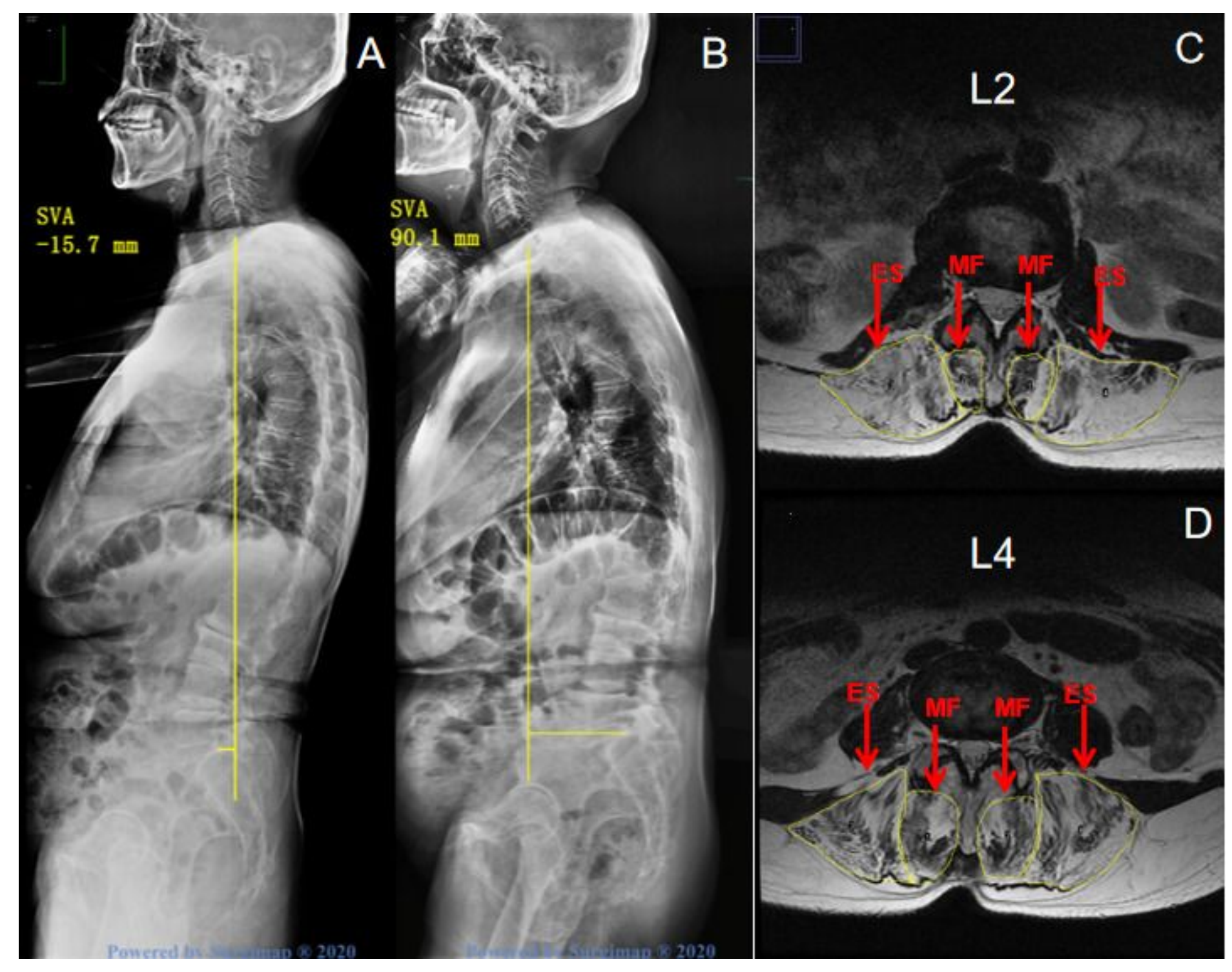

\section{Figure 4}

Case 2. Female, 60 years old. A: Lateral full-spine standing radiographs at initiation shows normal SVA. $(S V A=-15.7 m m) B: L a t e r a l$ full-spine standing radiographs after 10-minute walk test shows dynamic increased SVA (SVA $=90.1 \mathrm{~mm}, \triangle S V A=105.8 \mathrm{~mm}) \mathrm{C} \otimes \mathrm{D}$ :Severe fat infiltration and paravertebral muscle degeneration at both $L 2$ and $L 4$ levels.

\section{Supplementary Files}

This is a list of supplementary files associated with this preprint. Click to download.

- Table.doc 